\title{
LA RACIONALIDAD DE LA GESTION PUBLICA EN EL CONTEXTO DE LA REFORMA DEL ESTADO (*)
}

\author{
Conrado Ramos (**)
}

\section{PRESENTACION.}

A partir de la reinstauración democrática, en el Uruguay, se debate intensamente sobre el proceso de Reforma del Estado en el sentido de su necesaria redimensión hacia un Estado eficiente.

Este debate se genera a partir de la prolongada crisis del sector público que produce problemas muy graves con respecto al procesamiento de demandas de la sociedad y plantea un reclamo de transformación en las modalidades de gestión pública.

A la crisis de largo plazo de nuestro sector público, debemos añadir las severas restricciones económicas por las que vienen atravesando nuestras democracias latinoamericanas.

Ello determina alternativas de decisión sumamente cambiantes, resultando necesario el diseño e implementación de políticas públicas de alta sofisticación.

Se estaría explicando de esta manera, la relevancia que la Reforma del Estado tiene en estos momentos, en la agenda político y académica de la región.

En el Uruguay, existe consenso entre los distintos actores sociopolíticos acerca de la necesidad de un redimensionamiento estatal.

Pero el consenso entre ellos se limita a constatar el diagnóstico de situación, sin poder extenderse a las explicaciones (cómo y porque se llegó a tal situación) y por ello tampoco a las terapias para hacer frente a la crisis.

Muy sumariamente diremos que el enfoque neoliberal hace la crítica del papel muy crecientemente interventor del Estado en las esferas externas al subsistema político (subsistema económico y sociocultural), tratando por su parte, de reducir y de rechazar las pretensiones que la sociedad civil hace al Estado, derivándolas al mercado.

En términos de Hirschman, podríamos decir que se refuerzan los mecanismos de salida, propios de la ciencia económica.

El enfoque estatalista, por el contrario, busca aumentar la capacidad de intervención y realización por parte del Estado, ya sea por medios organizativos cualitativos o por medios fiscales cuantitativos.

Usando nuevamente la terminología de Hirschman, en este último enfoque se refuerzan los mecanismos de la voz, propios de la política.

Entre el estatismo tradicional y la lógica de la privatización, parecería haber en el Uruguay de los noventa, en el nivel de los actores y de ciertos debates estratégicos, algunas alternativas de redefinición del espacio público.

Dichas estrategias buscan combinar equilibradamente los mecanismos de transferencia de demandas al mercado y promoción del mismo, junto a los de mejoramiento de la gestión administrativa del Estado, siendo ambos mecanismos instrumentados en el marco de la negociación política.

Cabría decir entonces, que se busca hacer una productiva utilización conjunta de los mecanismos políticos y de mercado.

Los efectos de este proceso alternativo de reforma comienzan a mostrarse en el Uruguay, atravesando a todo el sistema político nacional siendo afectadas las tradicionales formas de vinculación entre el Estado y la sociedad civil. Ello resulta en nuevas formas de representación y articulación de intereses que estarían apuntando a redefinir las fronteras entre lo público y lo privado.

Estas alternativas de redefinición del espacio público, tendrían un diagnóstico previo en común, y este es que la falta de competencia, en la forma de monopolios públicos y privados, restringió severamente la eficiencia en la producción y asignación de recursos.

Por otra parte, la eficiencia exige flexibilidad organizacional, es decir, capacidad de adaptación rápida al contexto o lo que en Teoría Política tradicionalmente se conoce como la reducción de incertidumbre.

Sólo si se cuenta con un Estado con alta flexibilidad organizacional se puede promover una auténtica fuerza

\footnotetext{
(*) Trabajo presentado al Seminario "Reforma del Estado: Más allá de la privatización, organizado por FESUR, Oficina Nacional del Servicio Civil, PRONADE y CLAEH, Montevideo, Uruguay, 10 y 11 de septiembre de 1992.

(**) Investigador del Instituto de Ciencia Política de la Facultad de Ciencias Sociales de la Universidad de la Republica 0. del Uruguay.
} 
empresarial (pública y privada) que lidere los cambios que modernicen el aparato productivo.

El objetivo de este trabajo es presentar, en este contexto de redefinición de lo público, el análisis de algunas de las propuestas y transformaciones que comienzan a observarse al interior del subsistema de Administración Pública.

El estudio de algunas de las principales reformas que se vienen produciendo en la Administración Pública, nos permiten suponer que en este proceso de cambio predominan ciertos criterios de racionalidad económica.

Dichos criterios apuntan a mejorar la eficiencia de la gestión pública en la prestación de servicios, en su nuevo rol de dinamizador del aparato productivo público y privado.

Este cambio de orientación en los fines del Estado, producto de la crisis de gestión del Estado social, contribuirá a explicar por qué también estaría cambiando la forma de procesarse la Reforma Administrativa.

La actual Reforma Administrativa recoge en buena medida, las propuestas de racionalización y modernización de la Administración Pública uruguaya, previas a la Reforma del Estado.

Dichas propuestas pueden ser rastreadas en los Informes elaborados sucesivamente por John Hall, en 1954, la Comisión de Inversiones y Desarrollo Económico (CIDE), en 19ó5 y por Oscar Oszlak en 1972.

Sin embargo, a partir de la recodificación que se viene operando en los fines del Estado, para lo que debe contar con cierta flexiblidad organizacional, la actual Reforma Administrativa, si bien recupera aquellas propuestas de racionalización y modernización administrativa, aparece ahora, priorizando los procesos de desburocratización y de gerencia del Estado.

Esta Reforma Administrativa, que es ahora una de las aristas, y podríamos decir instrumento de la más global Reforma del Estado, pretende preparar a la Administración para que su actividad sea funcionalmente más racional a la Reforma del Estado.

Ello implica entre otras cosas, un cambio en las formas fundamentales de dirección de la acción administrativa.

Este cambio de orientación en las actuaciones administrativas, le exige a la Administración, por un lado cambiar sus esquemas normativos de actuación, y por el otro, esta mayor autonomía decisional exige una Administración responsable de sus actuaciones.

Con respecto al primer punto, trataremos de demostrar que se ha producido en los esquemas normativos de la Administración Pública, la incorporación de una racionalidad político-sistémica, con una orientación funcional a las necesidades del subsistema económico, que flexibiliza la racionalidad burocrático-formal, con su clásica orientación legalista.

En el modelo burocrático-legal, la eficacia de la tarea administrativa, está dada por la subsunción segura de las actividades bajo premisas que no son revisadas.

En este modelo weberiano ideal, los inputs de la actividad administrativa, regulan el output, los que son resultados de la norma jurídica, de reglas codificadas de comportamiento y rutina, calculables de antemano por cualquiera de los afectados.

La cuestión que se viene planteando, es la de si este tipo de racionalidad administrativa, sigue siendo "racional", en el sentido de que responde a las exigencias y necesidades funcionales de un Estado eficiente.

Creemos que la pretensión de preparar a la Administración para cumplir adecuadamente los obJetivos de un Estado eficiente exige la flexibilización de estos criterios.

La racionalidad político-sistémica se orienta en cambio, a la persecución racional finalista de la eficacia y eficiencia de las actuaciones administrativas, es decir, no por el seguimiento de reglas sino por el logro de resultados funcionales.

Las premisas de la actividad administrativa son aquí, recursos (y no reglas) a utilizar desde el punto de vista de la adecuación para ciertas tareas.

Nos encontramos así, frente a un nivel más alto de racionalidad sistémica, donde la propia administración revisa sus inputs y de ser necesario los modifica, según los requerimientos del complejo entorno social.

Ello habilita un mayor margen de decisión ad-hoc y de selección para la realización de programas finalistas o de objetivos.

El cambio de orientación en las formas de actuación de la Administración, afecta también a lo que tiene que ver con la responsabilidad de sus actuaciones.

La clásica distinción funcional hecha por Luhmann, entre Política, como la esfera que produce legitimación por un lado, y la Administración, como la esfera que usa esa legitimación en la producción de decisiones vinculantes, en cuanto formaciones sociales concretas, ha perdido significación práctica.

Debemos pensar si la Administración al orientarse a la persecución racional finalista de sus objetivos, asumiendo los riesgos y responsabilidades que ello implica, no deberá buscar nuevas formas de legitimar sus decisiones.

El sistema político, se trate del gobierno o de los grupos sociales concretos, apoyaran tanto más a la Administración en sus fines, cuanto más dependan de la acción y del rendimiento de ésta.

La legitimidad de sus actuaciones, ya no vendrá dada por el cumplimiento a través del clásico procedimiento administrativo de lo que el poder político ha decidido de antemano, sino por la transparencia y el público reconocimiento de una actuación eficiente, tal como normativamente se le exige a la Política. 
En el desarrollo de esta investigación, hemos diferenciado tres áreas en donde se viene procesando la actual Reforma Administrativa. Ellas son:

- la racionalización de la Administración Pública como tal. - el proceso de desburocratización.

- la mejora de la gestión del sector de empresas públicas (SEP).

Se tratará de demostrar que estos procesos de Reforma Administrativa, están fuertemente comprometidos hacia el mencionado cambio en la orientación de las formas de actuación administrativa.

Observaremos entonces, que subyace a todos ellos el propósito de dotar a la Administración de recursos humanos y normativos para poder realizar tareas de programación y de selección de alternativas.

Serán una constante en el análisis de los casos, el cambio de racionalidad y la necesidad de legitimar sus actuaciones de quienes están embarcados en este proyecto de reforma.

Estamos dejando de lado por un lado a los procesos de Reforma del Estado que hacen a la descentralización, desconcentración y municipalización, y que hacen a los conceptos de democracia política. Dichos procesos merecen un análisis específico con un tratamiento ordenado del mismo.

Tampoco abordaremos el proceso de privatización, tan debatido en nuestra sociedad en base a fundamentos más ideológico partidarios que en base a un verdadero concepto de eficiencia. Sí, en cambio, se considerarán algunos casos de privatización periférica como parte del proceso de racionalización del sector de empresas públicas.

Una primera aproximación empírica a los focos de reforma que corroborarían nuestra hipótesis, se detendrá en un breve estudio de las líneas rectoras que han impulsado la gestión de la ONSC y del proceso de desburocratización a cargo de la PRONADE.

Ello incluye el trabajo de toma de conciencia que realizó la ONSC por la vía de seminarios y publicaciones correspondientes a los mismos, como documentos del traslado de la problemática desde la Reforma Administrativa a la Reforma del Estado.

Un nivel interesante para comprobar el cambio de orientación en las formas de actuación de la Administración, se observa en los proyectos de reforma de la gestión de las Empresas Públicas.

Nos hemos decidido por el análisis del proyecto que el Poder Ejecutivo ha presentado y se haya a consideración del Senado.

\section{EL CAMBIO DISCURSIVO DE LA REFORMA ADMINISTRATIVA.}

\section{LOS INFORMES DE REFORMA ADMINISTRATIVA.}

Como ya hemos afirmado antes, los intentos de Reforma Administrativa en el Uruguay, previos a la dictadura, a saber: el informe Hall (1954), el diagnóstico de Oszlak (1972), recomendaban básicamente que la acción administrativa pasase por un proceso de racionalización y modernización.

Se pretendía así que:

- se eliminaran los problemas relativos a la dirección, coordinación e integración de las organizaciones particulares del macrosistema organizativo de la Administración Pública.

- se eliminaran las incidencias político-clientelares en el sistema administrativo, creando un cuerpo de burócratas profesionales al estilo weberiano.

- la acción administrativa debía responder adecuadamente a las exigencias de planificación de un moderno Estado Social.

Cuando el objetivo de la reforma, era montar una Administración para el Desarrollo, lo que significaba básicamente, modernizar técnicamente, se aludía a la solución de los problemas que el macrosistema organizativo posee, relativos a la dirección, coordinación e integración de sus organizaciones particulares en un todo más amplio.

Es así que encontramos en los informes de Reforma Administrativa, semejanzas en sus diagnósticos que pasan por problemas de diferenciación funcional y política en la coordinación vertical y horizontal y en los principios de la organización burocrático-administrativa.

En el nivel de la diferenciación funcional horizontal (por ámbito de tareas), se presenta la acuciante necesidad de cooperación entre los ministerios para eliminar la superposición de tareas, denominándose a este intento de cooperación como "coordinación negativa".

En las disfuncionalidades de diferenciación funcional en la línea vertical, predomina la inadecuada definición de autoridades y responsabilidades que dificultan la conducción administrativa y la delegación de autoridad, produciéndose el conocido fenómeno de la sobrecarga de tareas rutinarias en los niveles superiores.

La división de trabajo entre los niveles administrativos, también depende de la relación entre el tipo de tarea y sus proporciones o la magnitud del ámbito de cobertura de una unidad administrativa.

Esto significa que un especialista para poder utilizar su pleno rendimiento de trabajo, sólo puede ser colocado en un nivel superior de la administración, dónde como consecuencia del ámbito mayor de cobertura, se producen con más frecuencia los casos correspondientes.

La insistencia en contar con técnicos especialistas que asesoren a los niveles más altos de la administración, que observamos en estos informes, se desprende de la característica funcional mencionada.

Consideremos ahora, los problemas respecto de las cuestiones organizativas relativas a los principios de la organización administrativa.

La forma de organización de los departamentos adminis- 
trativos puede calificarse como predominantemente "burocrática", ya que se emplean las características estructurales con que las definió Max Weber:

1. Jerarquía establecida con exactitud.

2. Sistema de líneas verticales de comunicación.

3. Porcentaje reglamentado de trabajo, basado en la especialización.

4. Sistema de principios que determina derechos y deberes de los miembros de la organización.

En el detalle de los diagnósticos aquí considerados, apreciamos la insistencia en señalar la distancia observada en el funcionamiento de la Administración Pública uruguaya respecto a este tipo ideal de modelo organizativo de acción social.

Los informes al percibir rigideces, conservadurismo e inflexibilidad en el desarrollo de las tareas en la Administración Pública uruguaya, tienden a asimilar estas deficiencias en la implementación de una correcta burocracia racional legal, a fenómenos tales como: el clientelismo, falta de capacitación de los funcionarios, fomento de la informalidad, exceso de formalismos y reglamentaciones, ausencia de una verdadera carrera administrativa y de una adecuada remuneración por la jerarquía del cargo ocupado e inamovilidades excesivamente rígidas.

Estas deficiencias estructurales, marcadas por los informes, provienen de las desviaciones que la Administración Pública uruguaya presenta frente al modelo burocrático ideal, lo que ciertamente ha sido un factor negativo para su productividad.

Las irracionalidades de la acción administrativa no eran atribuídas en los informes (salvo el de Oszlak), más allá de las deficiencias anotadas, a los rasgos que propiamente se manifiestan en el modelo normativo de la racionalidad burocrático-formal.

Los más recientes informes de Reforma del Estado, que tratan las cuestiones relativas a la gerencia del Estado y desburocratización, recogen las anteriores criticas a la Administración Pública uruguaya mediante estrategias de racionalización.

Pero incorporan, y notamos aquí un cambio en la filosofía de la reforma las críticas a la presente irracionalidad funcional del mismo modelo de racionalidad burocráticoformal ideal de Weber, que trabaría un proceso de flexiblidad organizacional como el que esta en cuestión.

De esta manera toman recientes trabajos de la Sociología de las Organizaciones (Crozier, Mayntz, Offe), y sus análisis del problema del "burocratismo" al interior de las organizaciones complejas, señalando los círculos viciosos que se crean en ellas debido a la rigidez, el ritualismo y la impersonalidad del modelo burocrático ideal.

Creemos que el modelo burocrático-formal ha perdido racionalidad funcional con respecto a la distinta orientación que toman las actuaciones administrativas en el proceso de Reforma del Estado hacia un Estado eficiente.
Es claro que los informes Hall, CIDE y Oszlak, eran diagnósticos sobre la administración Pública y no de Reforma del Estado, ya que no se asistía entonces, a un verdadero cuestionamiento del rol del Estado.

Pero cuando se cuestiona el deficiente funcionamiento de un Estado burocratizado y reglamentarista, que traba el necesario proceso de planificación selectiva de una moderna Administración, además de racionalizar su estructura administrativa, se deben revisar los mismos esquemas normativos de su actuación típico ideal.

\section{LOS TRABAJOS SOBRE REFORMA DEL ESTADO.}

Hemos adelantado ya que actualmente, la Reforma Administrativa, aparece como una de las dimensiones (aunque de vital importancia) de la más global Reforma del Estado.

En los años 80 surge una corriente que pone en tela de juicio el rol del estado y su eficiencia como productor y que propugna reducir el tamaño del estado y su intervención en la vida económica y mejorar su eficiencia.

Este enfoque se generalizó y Uruguay no fue ajeno a éste, por lo que se empezaron a aportar algunas reflexiones e ideas sobre alternativas para la modernización y la reforma de nuestra burocracia estatal, en el marco de esta discusión.

Nos ocupan aquí, aquellas propuestas de reforma que no pueden definirse claramente como partidarias de ser, usando una terminología cara a Klisberg, o bien, "usuario final de tecnología”, como sí ocurrió bajo el paradigma desarrollista, o bien marcadas por el "sesgo privatista", bajo el dominante enfoque neoliberal.

En este nivel de análisis ubicaríamos la afirmación de Sayagues de que para la Reforma Administrativa es tan funesto el excesivo énfasis en la dimensión tecnológica del asunto, como una visión economicista del Estado que omita considerar la necesidad de soportes administrativos eficientes.

Haremos referencia entonces, a las propuestas de Modernización del Estado a partir de los 80, que toman tres vertientes principales:

a) la racionalización de la Administración Pública como tal.

b) la crítica al burocratismo y los programas de desburocratización.

c) La mejora de la gestión en el sector de empresas públicas (SEP).

Se destaca en este tipo de propuesta de reforma, la conciencia que sus impulsores tienen, de que los éxitos en esta materia sólo se consiguen mediante cambios graduales, sin considerar a la reforma de la administración como un paquete unitario.

Esto se debe, en parte, a que no se percibe a la Administración Pública como un todo homogéneo, distinguiéndose en cambio por las distintas racionalidades que 
tienen sus actores, dependiendo del organismo que integre y de las funciones que allá desempeñen.

Encontraremos entonces, en estas propuestas de reforma, el aludido cambio en la orientación de las formas de actuación administrativa.

Con ello advertiremos el cambio en los criterios de racionalidad de las actuaciones administrativas y la necesidad de legitimación supralegal que las mismas experimentan.

Las propuestas de Modernización del Estado uruguayo posteriores a la reinstauración democrática, fueron tratadas en los libros:

\section{- "Gestión del Estado y Desburocratización"}

Oficina Nacional de Servicio Civil (ONSC) - ILPSS

C. Freitas y R. Franco (Compiladores) (1989)

- "La Reforma del Estado en el Uruguay"

Oficina Nacional de Servicio Civil (ONSC)

\section{Freitas (1988)}

En estos trabajos, puede ser rastreado el corpus teórico (background) que apoyo los procesos de reforma en estudio.

\section{LA RACIONALIZACION ADMINISTRATIVA.}

La racionalización administrativa es definida como la acción que tiene por objetivo la propia administración, buscando aumentar su eficiencia y productividad.

Las reformas que se han propuesto abarcan diversos campos, aunque tienen en común el supuesto de que la Administración Pública puede perfeccionarse para cumplir sus tareas más eficientemente.

La Oficina Nacional de Servicio Civil (ONSC), a partir de su reinstalación en 1985 como responsable de la modernización del Sector Público viene proponiendo una serie de medidas en ese sentido.

Para poder llevar adelante dichas propuestas, la ONSC ha venido realizando un trabajo sistemático de concienciación y cambio de mentalidad, tanto a nivel político como administrativo, a través de becas al exterior y seminarios de muy buen nivel técnico.

Este organismo, desde. el año 80 hasta el 90, ha sacado una serie de publicaciones cuatrimestrales (Revista de Administración Pública, 13 volúmenes) donde se documenta integramente su labor hasta la fecha.

En el Editorial Volúmen $\mathrm{N}^{\circ} 10$ de la Revista, El Dr. R.C. Freitas, por entonces Director de este organismo, realiza un balance de actuación hasta el momento.

Desde el año 85 al 89, se capacitaron 1400 funcionarios pertenecientes a lo que se conoce en Ciencia de la Administración como la "Alta Burocracia".

Se capacitó a a 800 funcionarios en los cursos de Administradores supervisores (con el apoyo de la Fundación Hans- Seidel) y 44 funcionarios participaron en los cursos de Altos EJecutivos, (con la asesoría de la ENA de Francia).

Se capacitó también intensivamente a los Gerentes de las Empresas Públicas, a nivel de División (con el apoyo de la Hans- Seldel), logrando consolidar un pensamiento gerencial que pone el acento en la eficiencia y en criterios de costo/beneficio.

Se hicieron importantes avances en el sentido de racionalizar el número de funcionarios de la Administración Pública.

Para ello, se reformó el sistema de ingreso efectivo a la Administración Pública, habilitándose únicamente el ingreso a los puestos técnicos de la misma, mediante rigurosa selección por concurso.

Se persigue con ello, eliminar el recurso del clientelismo político en la Administración Pública y terminar con el uso irracional (desde el punto de vista de la "productividad" administrativa) del empleo público como amortiguador del impacto del lamentable fenómeno del desempleo.

Se reformó el tradicional sistema de calificaciones y ascensos, conocido como de "antiguedad calificada", bajando la evolución de la ambiguedad desde el $50 \%$ a un $20 \%$ en el Gobierno Central y un $5 \%$ y $10 \%$ en las empresas públicas, según el Manual de Calificaciones del año 1984.

Con todas estas disposiciones se buscó promover una burocracia "responsable" de sus actuaciones (en términos de Eisenstadt seria una administración volcada a los servicios), con elevada capacidad técnica y de toma de decisiones.

Los impulsores de la Reforma conscientes del axioma lanzado por Crozier, de que la sociedad no se cambia por decreto, buscan crear un cuerpo de "gerenciadores del cambio" al interior de la misma Administración (property administration)

La racionalidad técnica y la burocrática no tienen porque seguir sendas separadas en un contexto en que la Administración busca reacomodar sus relaciones con los elementos dinámicos del exterior a su subsistema.

La figura del "Gerente del Estado", quien brinda al gobernante y su equipo, información "oportuna, fluida, veraz, objetiva y relevante", para formular las políticas públicas, no tiene necesariamente que pertenecer a un staff técnico por fuera de la carrera administrativa.

Por otro lado, se deben brindar incentivos a los mas capaces para ascender en la carrera administrativa, más allá de su antigüedad. Los ascensos como recompensa a la capacitación actuan en ese sentido.

Pero el problema de las bajas remuneraciones del Sector Público sigue siendo un escollo difícil de salvar.

Resalta la vigencia del problema del achatamiento de la pirámide salarial entre el escalafón más alto y el más bajo, y aun dentro del mismo escalafón en la carrera administrativa. 
El análisis hecho por la PRONADE en el año 90, acerca de la fuga de personal capacitado de la Empresa Pública hacia el Sector Privado, demuestra que este es un problema que afecta principalmente a los cargos técnicos de la Administración, quienes reciben su preparación en la Administración Pública para luego ser absorbidos en la etapa en que mayor rendimiento pueden ofrecer, por el sector privado (24 a 40 años).

La promoción de una Alta Burocracia con fuerte capacidad de planificación, apunta en el sentido de lo que venimos planteando aquí como hipótesis de trabajo.

El fenómeno de la "Gerencia del Estado", con administradores que realizan verdaderas tareas de planificación con orientaciones selectiva, y con fuerte necesidad de que sus actuaciones se reconozcan no solo en el terreno de la legalidad, sino en el terreno real de la economia, diluye las anteriores fronteras de Política y Administración.

En esta búsqueda de eficiencia, los altos niveles burocráticos vinculados a las tareas de gerencia, suelen violar los principios del modelo burocrático-formal.

No obtienen siempre su información formalmente ni respetando la línea jerárquica. Mantienen contactos personales y aplican su inventiva para resolver casos ad-hoc, rompiendo con las premisas de rutinización e impersonalidad del modelo burocrático ideal.

Los contactos personales y la atribución de responsabilidades de gestión más allá de la legalidad, evitan el desinterés por las metas de la organización y los conocidos "círculos viciosos de la burocracia" (Crozier, "El fenómeno burocrático").

Klisberg ha citado un estudio del Instituto Técnico de Massachusset (MIT) donde se afirma: “es más productivo tener una fuerza de trabajo cooperadora y no una tecnología muy sofisticada".

Se debe reconocer a la Administración Pública como una trama de intereses en conflicto, donde es imprescindible la negociación y la búsqueda de acuerdos para promover cambios organizativos sustanciales.

\section{EL PROCESO DE DESBUROCRATIZACION}

El actual programa de desburocratización, si bien puede parecerse mucho a los tradicionales proyectos de racionalización y de simplificación administrativa, significa ante todo reducir la interferencia del Estado y el exceso de reglamentación de la activad económica.

Se dirige directamente al interés del usuario o consumidor del servicio público con el objetivo de aliviarlo de exigencias excesivas y asegurarle un buen servicio.

Es entonces, un cambio cultural mas que técnico, destinado a modificar la cultura organizacional de la burocracia, donde el apoyo político es fundamental para que cristalicen los intentos de cambio.
Durante el período de gobierno del Presidente Sanguinetti (85-90), la ONSC realizo experiencias piloto de desburocratización en las Intendencias del interior de la República, eliminando casi un millón de tramites burocráticos y 500.000 firmas anuales.

También en ese período, con la asistencia de la ONSC, se aprobaron manuales de procedimientos burocráticos en la Administración Nacional de Puertos y se reinstitucionalizó el Banco de Previsión Social.

El gobierno del Presidente Lacalle, iniciado en marzo del 90, creó mediante el Decreto 257/990 de mayo de ese mismo año, el Programa Nacional de Desburocratización (PRO.NA.DE) ( cuya coordinación y ejecución pertenece a la Secretaría de la Presidencia de la República), siendo su actual director el Dr. Alberto Sayagues.

Se pretendió con ello, darle mayor dinamismo al proceso de desburocratización, mediante la simplificación de Tramites, facilitar la atención de los usuarios de los servicios públicos y reducir la interferencia del gobierno en la actividad privada.

Si se trabaja menos y mejor, si se deja de hacer lo inútil y se hace mejor lo útil, se incrementaría la productividad.

Esta noción de desburocratización, tan próxima a la desregualación, pretende ser un remedio al burocratismo, que es la burocratización como enfermedad.

Según un experto en Derecho Administrativo como lo es el Dr. Carlos Delpiazzo, en el prólogo del libro de Alberto Sayagues "Reforma del Estado, El Nuevo Régimen de Compras en la Ley de Contabilidad y Administración Financiera y su Texto Ordenado (TOCAF)", el problema del burocratismo se manifiesta a través de los siguientes síntomas:

- las jerarquías no toman decisiones según criterios de eficiencia

- se está frente a una estructura que ha perdido sus objetivos y es incapaz de trazarse metas

- los objetivos particulares de la administración prevalecen por sobre el de los administrados

- no hay adecuados niveles de supervisión para las tareas

- no hay una adecuada planificación

- se sustituye la información clara, sintética, fluida, veraz y oportuna, por el papeleo confuso

- se estira la pirámide de jerarquías evitando la decisión los controles ahogan la iniciativa

- las regulaciones se transforman en mecanismos de coerción supra administrativos

- la legitimación se obtiene de la propia burocracia y no del sector real de la economía

Las causas de estos síntomas se han detectado, y aquí si muy claramente, ya no solo en una incorrecta aplicación de los principios burocrático-formales del modelo ideal, sino en la irracionalidad de esta misma racionalidad que ha dejado de ser funcional al sistema. 
La rigidez propia del modelo burocrático tradicional, no permite actuar según las particularidades del caso, frenando lo que hemos dado en llamar "la flexibilidad organizacional".

Queda puesto también en cuestión, el centralismo, como la antítesis de la delegación, evitando esta última que las actividades mas rutinarias se concentren en los niveles superiores. La delegación permite que las decisiones no se estiren siempre hacia las jerarquías superiores.

El ritualismo, lleva a seguir determinados trámites y exigir ciertos requisitos sin que nadie sepa su razón de ser.

La ausencia de ritualismo en los actos administrativos, solo es posible si apunta a la materialidad de la norma y no solo a su forma, es decir, si se abandona el formalismo.

El conocimiento de la sustancia de la norma por parte del funcionario actuante, sumado a una autoridad previamente delegada, lo capacita para interpretar y decidir con cierta informalidad, la que siempre es en favor del administrado, las cuestiones que pueden suscitarse en la aplicación de las disposiciones pertinentes.

La tradicional desconfianza se contrapone al principio de la veracidad, utilizando este último principio, la declaración jurada como un adecuado instrumento para las economías de los usuarios y funcionarios.

El Decreto 500/991 sobre el Nuevo Procedimiento Administrativo, que rige para toda la Administración Central, modifica el anterior Decreto ó40/973, incorpora estos principios de desburocratización, para mejorar la eficiencia de las actuaciones administrativas.

Mediante estas reformas en los principios de la burocracia-formal, la Administración estaría revisando sus propios inputs, y modificándolos en favor de los intereses del administrado.

Ello no significa, entonces, una discrecionalidad absoluta para actuar como quiera sin sujetarse a formas preestablecidas, como lo señala el artículo 90 de dicho decreto. Lo que el formalismo moderado autoriza al funcionario, es a la inobservancia de exigencias formales no esenciales y que puede ser cumplidas posteriormente.

El Derecho Administrativo en el Uruguay, contempla aquellos casos en que la Administración actúa discrecionalmente, con el fin de otorgarle al funcionario administrativo, un margen de apreciación de los textos legales, (sobre "actos discrecionales" y actos "reglados" ver: Sayagues Laso, E.,Tratado de Derecho Administrativo", Montevideo, 1974).

Pero este mecanismo legal se ha mostrado insuficiente frente a las contingencias que diariamente se le plantean a una Administración crecientemente volcada a los servicios, debiendo modificar su normativa a fin de atender los reclamos del ambiente.

Para producir una adecuada adaptación a las exigencias del ambiente, la Administración ha debido modificar su misma normativa.
La PRONADE es consciente de que el éxito de su gestión depende de factores tales como la focalización de los esfuerzos por áreas de eficiencia, una profundización del debate sociopolítico para conseguir legitimidad a sus logros y vencer resistencias y un fuerte nivel de participación ciudadana que observe la transparencia de la gestión pública.

\section{MEJORA EN LA GESTION DE LAS EMPRESAS PUBLICAS}

En un trabajo del año 78, llamado "La inserción de las empresas públicas en el aparato estatal uruguayo", Solari y Franco afirman que el llamado Sistema de Empresas Públicas (SEP), refleja, aunque no mecánicamente, al sistema político vigente, el que le otorgara una ideología justificatoria que define sus objetivos, los recursos que deben otorgársele para cumplirlos y las limitaciones que debe enfrentar.

En la medida en que se están produciendo fuertes modificaciones en el sistema político uruguayo, donde lo que está en discusión son las líneas divisorias y los relacionamientos entre el Estado y la Sociedad Civil, cabe esperar que también quede afectado el marco ideológico del SEP.

En un trabajo posterior, el mismo Franco sostiene que que aún si se alcanzaran éxitos importantes en el proceso de privatización, parece realista pensar que subsistirá un sector público amplio, lo que obliga a realizar un esfuerzo de modernización mejora del desempeño económico y social del SEP.

Las propuestas de mejora de la gestión de las empresas públicas que aquí analizaremos, no centran sus esfuerzos en cómo controlar y utilizar a las empresas públicas (lo que no implica dejar de lado el problema de la autonomía), sino que focalizan su atención en como recuperar el desdibujado espíritu empresarial.

Es sabido que en su período constitutivo, período que se extiende hasta el golpe de Estado del 33, el concepto de autogestión exigía eficiencia a efectos del mantenimiento del servicio.

El concepto de eficiencia de la empresa pública, depende de los fines que le otorgue el sistema político, siendo definido en el período batllista como la combinación de una gestión financiera exitosa, sumado a la función de redistribución de la riqueza nacional que asumía ese estado de compromiso.

Los beneficios derivados de la empresa pública para el Estado y la sociedad como un todo en ese período, permitieron la capitalización de las empresas mediante la reinversión de sus ganancias.

Simón Hanson, economista nada afecto a la intervención estatal en la economía, en su libro "Utopía en Uruguay", sostiene que las empresas públicas eran administradas de tal manera que soportaban la comparación con las más eficientes empresas privadas.

Contaban para ello con la existencia de un grupo de high 
civil servants de muy altas cualidades por un lado, y por el otro, debían demostrar su eficiencia si querían mantener sus niveles de autonomía, ya que muy difícilmente podrían mantenerla si recurrían permanentemente al Poder Ejecutivo en demanda de fondos para cubrir sus déficits.

La crisis de la economía nacional luego del período constitutivo, afecto la eficiencia del sector, el que pasó a ser absorbedor de mano de obra desocupada, a lo que se agregó el fenómeno del clientelismo político que le hizo perder autonomía con respecto a los partidos políticos.

\section{ANALISIS DE LAS PROPUESTAS}

Ensayaremos una clasificación de las propuestas de mejora de la gestión de las Empresas Públicas que se recogen en los trabajos de Reforma del Estado que venimos analizando.

Estas reformas en la gestión de la Empresa Pública, se han elaborado con el objetivo de recuperar su eficiencia perdida, en el supuesto de que se deben incorporar reglas de mercado al interior de la misma.

Comprobaremos que estas propuestas están estrechamente vinculadas al proceso de desburocratización y al de capacitación del servicio civil.

Nuestra hipótesis de trabajo recogerá en el análisis de las propuestas, elementos empíricos suficientes como para afirmar que se produce también aquí una modificación de los principios que guian la actividad administrativa.

En el caso de la Empresa Pública, se está frente a un área de la gestión estatal donde predomina por su misma naturaleza, una racionalidad económica, y en consecuencia, la superación de la racionalidad burocrático-formal, encuentra necesidades funcionales mucho más fuertes que en otros sectores de la Administración Pública.

Es necesario advertir, que el hecho de introducir reglas de mercado al interior de la empresa pública, nos conduce a la discusión acerca de los fines que persigue el SEP, los que ya hemos dicho que dependen a su vez del sistema político.

Esta discusión esta presente en el debate en el Uruguay de los noventa.

Entre aquellos que no proponen la eliminación del SEP y a su vez son partidarios del mecanismo de la competencia, debemos hacer una distinción (que tendrá sus gradaciones) entre los que se inclinan por la eliminación de la función de redistribución de la riqueza social que realiza la empresa pública, y los que piensan que eficiencia y política social no son políticas encontradas.

Para estos últimos, se debe analizar muy cuidadosamente los fines sociales que distorsionan los costos de las empresas públicas.

El costo que origine estos fines no empresariales, debe ser cuantificado y resarcido por el Gobierno Central a la empresa y no trasladado al precio de sus servicios.
Existe pues, entre los partidarios de la mejora de la gestión del SEP, cierto consenso respecto de las areas en que es preciso introducir modificaciones, pero es preciso advertir acerca de los distintos criterios de aplicación práctica que las mismas pueden ofrecer.

Pini y Sayagues, en su trabajo "Desburocratización y desestatización", han detectado cuatro áreas en el sistema jurídico del SEP, que trabarían una gestión eficiente.

El Sistema de Personal, no tiene un adecuado sistema de incentivos y castigos de la actividad del funcionario. Para ello es necesario modificar el régimen estatutario de los funcionarios.

En el análisis del Proyecto de Mejora de la Gestión Pública y en lo actuado en UTE, veremos como se ha avanzado al respecto.

El Sistema de Compras. El Estado compra mal, tarde y paga mucho más, lo que es muy crítico en una actividad empresarial.

La Ley de Compras aprobada en la Ley de Presupuesto de Diciembre del 90, se ofrece como solución ả respecto, siendo un claro ejemplo de la interconexión entre los distintos focos de reforma que tratamos aquí.

En esta ley, se ofrece un mayor margen de autonomía a las gerencias (especialmente las de Abastecimiento), pudiendo considerar el administrador las particularidades de cada caso.

El Sistema de Control que actualmente hace la Administración Pública sobre sus actuaciones, es un culto a la forma y no a la calidad de la gestión. Se propone sustituir el control de legalidad por el de gestión.

Una administración que programa por objetivos, con un margen de discrecionalidad elevado, necesita un sistema de control más alla de la simple observancia legal de sus rendimientos administrativos.

En otro orden de consideraciones, el aumento de remuneración de las gerencias es un requisito indispensable para la mejora de la gestión de estos monstruos organizacionales. Piensese en UTE que emplea 11.000 funcionarios.

La resistencia a ello radica en el temor al efecto arrastre, que produjese una escalada inflacionaria. En opinión de los expertos es un riesgo cuantificable muy inferior al costo de lo que significa la fuga de los gerentes capaces del sector público.

En lo que hace a la relación entre la empresa y el gobierno, la excesiva autonomía (frente al gobierno y no frente a los partidos) que gozaba la empresa antes de la reforma constitucional del 87 , hacía que sus decisiones empresariales, por su impacto en la economía, distorsionaran la política económica y financiera del gobierno.

Los acuerdos de Contrato-Programa entre la empresa pública y el gobierno, compatibilizarían una centralización hacia el gobierno de las políticas financieras y sociales de la empresa, con una descentralización de la gestión de la empresa. 
Ello daría lo que hemos dado en llamar una Administración responsable o volcada a los servicios, que evitaría una subordinación extrema a los intereses partidarios o de un grupo social en particular, o una autonomía excesiva a favor de los intereses únicos de la propia organización.

Por último, las propuestas de mejora de la gestión, recomiendan a la empresa focalizar sus esfuerzos y no derrocharlos en actividades que no son de su especialidad.

Las privatizaciones periféricas serían el remedio a la tendencia al autoabastecimiento. Pero muchas veces en la práctica se observa que el mercado no está preparado para absorber la nueva demanda que la empresa crea al transferir esas actividades al sector privado, con lo que la burocracia no se expande aquí por propia inercia, como es su naturaleza, sino por fallas del mercado.

Actualmente existe un Anteproyecto de Ley del Poder Ejecutivo que viene siendo objeto de tratamiento en el Senado que recoge algunas de estas propuestas y que estaría definiendo sustantivos cambios en la gestión de las Empresas Públicas.

Destacamos la radicalidad de los cambios en lo que hace a las orientaciones tradicionales de la burocracia, los que se observan en las modificaciones al régimen jurídico de las Empresas Públicas.

En lo concerniente al cuerpo gerencial se establece que las funciones de Gerente General y aquellas que se encuentren en los dos niveles gerenciales (División de Departamento o niveles similares) siguientes al de Gerente General y sus equivalentes, no estarán comprendidas en la carrera administrativa.

Este proyecto afronta la posibilidad de crear un nivel propio de gerencia administrativa, desvinculado de la carrera administrativa ordinaria, como una especialización desde la que se puede acceder tanto desde los niveles superiores de los distintos cuerpos superiores, como desde el sector privado, en una suerte de "open structure".

La asignación de estas funciones por parte de los Directorios, previo contrato de función pública a través de un proceso técnico de selección, se efectua por un plazo renovable de dos años.

El contrato de función pública que se realiza abiertamente, debiendo probar el postulante su idoneidad técnica y personal, busca ser un obstáculo al fenómeno del clientelismo político.

Por su parte, los Directorios, que estarían integrados por tres miembros, regirán su gestión en base al presupuesto y a los objetivos y políticas que se establezcan en los acuerdos o contrato-programas, que se efectúan entre el EJecutivo y los Directorios.

Los contrato-programas tendrán una duración de cinco años, pudiendo revisarse en común acuerdo según las condiciones del contexto económico y social.
El presupuesto anual, que deberá estar aprobado antes del ejercicio económico, dependerá de las condiciones del contrato-programa, que incluyen la fijación de precios y tarifas de sus bienes y servicios.

El cumplimiento del presupuesto será analizado trimestralmente con las Gerencias involucradas y será controlado por el Tribunal de Cuentas en base a los indicadores confeccionados por la Oficina de Planeamiento y Presupuesto (OPP), que permitan evaluar la gestión administrativa, financiera y gerencial de la empresa.

Se sustituye así el anterior control de legalidad por un adecuado control de gestión. Constituye otra evidencia en favor del cambio de racionalidad de la gestión pública, preocupada mas por perseguir objetivos finalistas y hacerse responsable por sus éxitos o fracasos, mas que por seguir al pie de la letra ciertas disposiciones que le pudiesen ser impuestas.

Una vez aprobados los contrato programas, los indicadores y el control de gestión, los directores de las empresas, podrán suscribir contratos de gerenciamiento con los gerentes, a los que se les exigirá una dedicación full-time y en caso de cumplimiento de los objetivos previstos, se les retribuirá con compensaciones especiales.

Las compensaciones especiales para los cargos de gerentes, pretenden recompensar por fuera de las achatadas pirámides salariales del sector público, la enorme responsabilidad que conlleva su función.

Es mas caro perder un gerente formado a un alto costo en la empresa pública, y que de realizar una buena gestión le estaría ahorrando cifras muy importantes al Estado, que otorgarle una excelente remuneración.

Los principios burocráticos vuelven a quedar violados en este caso por la invasión de principios organizacionales propios de las empresas privadas, en la línea del management.

Los contratos de productividad se hacen extensivos en el artículo 90 de la ley a todo el personal subordinado, cuando estuviere previsto en el contrato-programa, los que podrán ser financiados hasta con el $50 \%$ de las economías proyectadas.

Con ello se estaría creando un sistema de incentivos para lograr que el funcionario se responsabilice por sus tareas, mas allá de la legalidad de sus actuaciones, comprometiéndose así con los fines globales de la empresa.

No nos extenderemos más en estas consideraciones debido a que el punto ya ha sido tratado en otra parte de este mismo trabajo.

\section{COMENTARLOS FINALES}

Hemos sostenidos que este tipo de reforma de la Administración Pública uruguaya, pretende crear las condiciones para el desarrollo de una burocracia de nuevo tipo, con mayor autonomía decisional, innovadora y responsable de sus actuaciones. 
Si ello fuere así, y este proceso se consolidara, cabría preguntarse como serían las futuras relaciones entre la clase política y esta burocracia.

Podríamos arriesgar un comentario de como percibimos que se ha venido desarrollando esta relación, con respecto a los elencos de gobierno.

En ese sentido, creemos que ha existido la voluntad política para llevar adelante dichas reformas, ya que las mismas son bien vistas desde la perspectiva de aquellos gobiernos que pretenden mejorar la eficiencia de sus políticas públicas.

Si bien es cierto que las reformas propuestas incrementarían la autonomía decisional de la burocracia, correlativamente aumenta su responsabilidad por la eficiencia de sus actuaciones.

El control de la gestión burocrática, sería hecho no sólo desde el gobierno, sino por los administrados, aunque habría que distinguir aquí las distintas organizaciones de intereses y sus dispares capacidades de control de la gestión pública.

Por otra parte, en una burocracia responsable de sus actuaciones, se identificarían tanto los méritos como las sanciones hacia aquellos que no se comprometen con los objetivos de la organización, lo que podría descomprimir en parte la presión sobre el gobierno.

Un último comentario está referido a la poca relevancia que en la propaganda gubernamental tienen los casos de mejoramiento de la gestión pública, a pesar de que han brindado apoyo político a dichos procesos.

No descartamos la presunción de que ello se explica a partir de la matriz ideológica neoliberal que subyacen a los programas de gobierno de las administraciones blanca y colorada.

\section{RESUMEN}

Analizando el caso uruguayo, Conrado Ramos trata de perfilar el nuevo papel que va a desempeñar un Estado eficiente. Centrándose en un aspecto más concreto de la reforma de la Administración Pública, el autor analiza la relación que se establece entre la nueva burocracia y la élite política, y los apoyos que los diferentes gobiernos dan al proceso de implementación de la reforma.

\section{ABSTRACT}

Studying the Uruguayan case, Ramos tries to define the role to be played by an efficient State. In one more concrete aspect of the Administration Reform, the author analyzes the relationship between the new bureaucracy and the political elites, and the supports that the different governments give to the process of implementation reform. 